\title{
SIMBOLISMO AUTOBIOGRÁFICO EN LA NOVELA "SAB" DE GERTRUDIS GÓMEZ DE AVELLANEDA
}

\author{
Brígida Pastor Pastor \\ Universidad de Surrey. Londres. Inglaterra.
}

Según Northrop Frye: "Most autobiographies are inspired by a creative, and therefore fictional, impulse to select only those events and experiences in the writer's life that go to build up an integrated pattern. This pattern may be something larger than himself with which he has come to identify himself or simply the coherence of his character and attitudes." Adhiriéndonos a esta definición de autobiografía, se podría considerar que la Autobiografia y cartas de Gertrudis Gómez de Avellaneda (1814-73) constituye una creación literaria. Aunque no disponemos de prueba documental que permita comprobar objetivamente si se trata de ficción o realidad, sí se pueden aportar datos evidentes que apoyen nuestro argumento. Así, si partimos de que su novela $S a b$, el relato de un mulato esclavo que se enamora de su ama blanca, es verdaderamente una obra de ficción, y puede demostrarse que guarda semejanzas con sus escritos autobiográficos, concluimos que, a la inversa, sus escritos autobiográficos también presentan aspectos novelísticos y, por consiguiente, la concepción de autobiografla de Northrop Frye es, en efecto, correcta. A través de un análisis comparativo entre la Autobiografia y cartas de Avellaneda y la novela Sab, se pueden establecer sorprendentes paralelismos, tanto de la caracterización de sus personajes como de la temática tratada. 
La Autobiografla y cartas de Avellaneda se compone de una serie de cartas que la autora escribió a su amado Ignacio Cepeda Alcalde. El tono de estas cartas es el de un amor no correspondido. Esta melodramática historia de amor entre la autora y el joven aristócrata andaluz comenzó en 1838, constituyendo un contínuo y constante juego comunicativo de amor histérico, ilusión, desilusión, desengaño, que se prolongará por unos 15 años, hasta 1854, cuando Cepeda contrae matrimonio, finalmente, con otra mujer. Pero ¿hasta qué punto podemos considerar que esta correspondencia amorosa está empapada de la actitud novelesca de la escritora? ${ }^{2} \mathrm{Si}$ adoptamos la concepción de autobiografía de Frye es difícil responder a esta pregunta, debido a la información tan limitada que poseemos sobre la vida de Avellaneda en aquel momento. Sin embargo, por una parte, el hecho de que estos escritos fueran concebidos como una serie de cartas amorosas nos hace pensar que Avellaneda muy probablemente recurriera a artimañas y disfraces literarios para cautivar al amante esquivo, convirtiendo estos apuntes autobiográficos en lo que podría denominarse una creación literaria. Por otra parte, en una etapa más madura de su vida personal y desarrollo artístico, nos encontramos con una Avellaneda convencional y más serena, alejada del espíritu rebelde que de sí misma presenta en su autobiografla y correspondencia amorosa. Además, sus escritos adquirieron un carácter más bien populista, llegando incluso a excluir sus dos primeras novelas, Saby Dos mujeres, de la edición de 1869 de sus obras completas ya que "no merecían el honor de ser incluidas en las prestigiosas colecciones de autores españoles." 3

Todo lo que conocemos de su etapa posterior sugiere que en realidad la Avellaneda de la madurez no tiene concomitancias con la figura que nos retrata en su Autobiografia y cartas. No obstante, a pesar de estas escasas observaciones, sugeridas por la realidad de lo que sabemos de su vida, quedan muy pocos datos evidentes que apoyen o rebatan la concepción de autobiografía que Frye nos presenta, a menos que exploremos lo que podríamos denominar el "simbolismo autobiográfico" revelado en su obra de ficción, es decir, a menos que examinemos las similitudes entre su indudable género novelístico y su posible autobiografía novelesca. El carácter novelístico de sus escritos personales parece vislumbrarse en su carta 53 a Ignacio Cepeda: "Respecto a lo que me consultas sobre mis cartas, sólo puedo responderte que no recuerdo exactamente lo que contienen. Ignoro si hay en esas cartas confidenciales cosas que puedan interesar al público, o si las hay de tal naturale- 
za, que deban ser reservadas." ${ }^{4}$ Estas palabras parecen reforzar la propuesta de nuestro argumento, ya que Avellaneda confiesa no recordar lo que ella misma había escrito en sus apuntes autobiográficos. Ello nos lleva a considerar la posibilidad de que el contenido de estos escritos fuera considerablemente ficticio.

Tanto en la Autobiografia y cartas como en la novela Sab hay un tema que destaca por encima de los demás: el tema del amor. Aunque, "el amor[...] no es, por supuesto, el amor en general, es un tipo de amor, el amor imposible, desdichado, romántico" (Mary Cruz, 81). Nicomedes Pastor Díaz ya habla dicho en $E l$ Conservador sobre la novela: "Sab es una novela americana, como su autora. No es una novela histórica ni de costumbres. Sab es una pasión, un carácter nada más..." " La acción argumental de esta novela desarrolla un conflicto sentimental: Sab es un esclavo mulato que está enamorado de su dueña, Carlota, quien a su vez esta prometida a Enrique Otway, hijo de un comerciante inglés. Por otro lado, Teresa, la prima huérfana de Carlota, siente una gran pasión por Enrique, auque éste la desconoce. Al enterarse Sab de que Enrique persigue, por encima de sus sentimientos, la dote de Carlota, planea con la ayuda de Teresa revelar a Carlota el engaño de dicha relación. Así Sab podría sońar con la remota posibilidad de conseguir el amor de su dueña. Teresa lo convence de lo contrario, concluyendo el relato con la muerte de Sab, la reclusión de Teresa en un convento y el matrimonio desgraciado de Carlota.

En $S a b$ se descubren varias proyecciones de la personalidad del "yo" autobiográfico de Avellaneda a través de los tres principales protagonistas: Sab, Carlota y Teresa, personajes muy bien diferenciados entre sí. Sab, cuyo nombre da título a la novela, aparece como un esclavo diferente a los de su raza. Así nos lo presenta Enrique Otway en las primeras páginas del relato: "Tu suerte, Sab, será menos digna de lástima que la de los otros esclavos, pues el cargo que desempeñas en Bellavista, prueba la estimación y afecto que te dispensa tu amo." "Además, ha recibido una educación similar a la del hombre blanco y, según dice, su madre "nació libre y princesa" (Sab, 138). Avellaneda presenta a Sab como un esclavo excepcional, tal y como ella se concibe a sí misma con respecto a las de su sexo: "Ya he dicho mil veces, que no pienso como el común de las mujeres, y que mi modo de obrar y de sentir me pertenece exclusivamente" (Autobiografia y cartas, 148). 
La autora escoge a una figura tan inverosímil como Sab porque, además de no tener nada que ver con el esclavo típico del momento, es, como ella misma, un ente sentimental, romántico e idealista, al que la capacidad de amar convierte en un personaje definido por sus sentimientos: " $\mathrm{Mi}$ amor, este amor insensato que me devora, principió con mi vida y sólo con ella puede terminar: los tormentos que me causa forman mi existencia: nada tengo fuera de él, nada sería si dejase de amar" (Sab, 259). El mismo sufrimiento y espíritu autodestructivo se desprenden de los sentimientos de la autora por el hombre que ama: "No sé qué influjo de fatalidad ejerces en mí. Has apagado mi talento y mi alegría, y hasta en mi corazón has abierto una fuente de amargura" (Autobiografia y cartas, 141). El esclavo, al igual que su creadora, es un ser "pacífico y rebelde, razonable y apasionado, práctico y sublime, violento y delicado, celoso y generoso, en fin, una mezcla tan íntegra que hace ilusoria la misma tarea de desentrañar sus componentes para señalar los posibles orígenes en otro discurso tradicional y binario." 7 Por otra parte, la intensidad de los sentimientos de Sab por Carlota lo convierten en un ser subyugado a causa del amor que experimenta hacia ella: "En vano quería apartar a Carlota de mi imaginación, y apagar la llama insana que me consumía: en todas partes encontraba la misma imagen, a todas llevaba el mismo pensamiento. Si en las auroras de la primavera quería respirar el aire puro de los campos y despertar con toda la naturaleza a la luz primera de un nuevo día, a Carlota veía en la aurora y en el campo: la brisa era su aliento, la luz su mirar, su sonrisa el cielo" (Sab, 245). Estos sentimientos tan obsesivos y subyugadores se encuentran reflejados en la correspondencia de Avellaneda: "Yo he mandado siempre en mi corazón y en mis acciones con mi entendimiento, y ahora mi entendimiento está subyugado por mi corazón, y mi corazón por un sentimiento todo nuevo, todo extraordinario" (Autobiografia y cartas, 124).

Tanto el personaje de Avellaneda como el de Sab se revelan como dos figuras románticas que parecen vivir en un mundo imaginario y novelesco, que aspiran a un ideal, a un imposible. Los dos están "totalmente enajenado[s] por lecturas románticas y caballerescas" que tan ávidamente devoran. ${ }^{8}$ Dice Avellaneda en su autobiografía: "[Mi] mayor placer era estar encerrad[a] en el cuarto de los libros, leyendo [mis] novelas favoritas y llorando las desgracias de aquellos héroes imaginarios, a quienes tanto [quería]" (Autobiografia y cartas, 44). La afición que Sab tiene por la lectura es otra 
muestra del paralelismo entre estos dos seres: "[Los] libros [...] han sido mi recreo en estos páramos, aunque también muchas veces han suscitado en mi alma ideas aflictivas y amargas cavilaciones" (Sab, 139). La escritora y su personaje parecen "profundamente influenciados por los ideales románticos y por la realidad de una sociedad donde tales ideales no tenían cabida" (TorresPou, 58). Sab intenta buscar en sus lecturas una esperanza a su desdichada realidad, al no ser correspondido por su dueña Carlota: "Cuando en mis primeros años de juventud Carlota leía en alta voz delante de mí los romances, novelas e historias que más le agradaban, yo la escuchaba sin respirar, y una multitud de ideas se despertaban en mí, y un mundo nuevo se desenvolvía delante de mis ojos. [...] ¡Cuántas veces las novelas que leía Carlota referían el insensato amor que un vasallo concebía por su soberana, o un hombre oscuro por alguna ilustre y orgullosa señora!... Entonces escuchaba yo con una violenta palpitación, y mis ojos devoraban el libro" (Sab, 311-12). Aún más, la ciega devoción que Sab siente por Carlota se asemeja a la que la escritora experimenta por su amado. Avellaneda expresa a Cepeda: "Tú serás mi Dios sobre la tierra, tú el dueño absoluto de esta alma apasionada" (Autobiografia y cartas, 49). La voz de Avellaneda se hace eco del amor de Sab hacia Carlota: "Soy esclavo suyo, y quiero vivir y morir a su servicio" (Sab, 140). No cabe duda de que "a medida que [la escritora y su personaje Sab] reafirma[n] e intensifica[n] su amor, viene[n] a simbolizar un ideal que es a la vez estímulo y perdición." ' En concordancia con la escritora, este personaje tiene una vida sin esperanza ninguna que lleva a $\mathrm{Sab}$ a morir cuando se convence de que no logrará el amor de Carlota. Avellaneda, aunque no muere de amor, sí expresa, con el mismo romanticismo trágico de Sab, sus deseos de morir ante la imposibilidad de conquistar el amor de Cepeda: "Adiós, ten compasión de una mujer que pudo ser algo en el mundo y que ya es nada. Ámame o mátame...; no hay para mí otra alternativa" (Autobiografia y cartas, 141-42). Es obvio que Avellaneda y Sab "tiene[n] un carácter muy vehemente, dominado por las pasiones, bien sea el amor, la desesperación, la ira, la compasión." ${ }^{10}$

La caracterización del personaje de Carlota encarna el estereotipo de heroína romántica y no deja de revelarse, al igual que la misma Avellaneda, como una víctima de su exceso de sensibilidad. Carlota, como Avellaneda, expresa su preocupación por los oprimidos y desventurados. Así dice esta heroína de la injusta realidad del esclavo: "Cuando yo sea la esposa de 
Enrique, [...] ningún infeliz respirará a mi lado el aire emponzoñado de la esclavitud" ( $S a b, 177)$. Y, además, añade hablando de su esclavo Sab: "Se ha criado conmigo como un hermano, tiene suma afición a la lectura y su talento natural es admirable" (Sab, 158). Del mismo modo, Avellaneda proclama su deseo de equidad entre todos los seres humanos: "Mi familia pertenece a la clase llamada nobleza, pero yo no pertenezco a ninguna. Trato al duque como al bufón. No reconozco otra aristocracia que la del talento." "1

Avellaneda y Carlota se manifiestan como dos mujeres insatisfechas emocionalmente, son víctimas de sí mismas por haber idealizado al hombre receptor de sus sentimientos. La escritora confiesa su predisposición romántica con respecto a sus primeras experiencias amorosas. De un caballero con quien su familia había concertado casamiento recuerda: "Prodigole mi fecunda imaginación ideales perfecciones, y vi en él reunidas todas las cualidades de los héroes de mis novelas favoritas" (Autobiografia y cartas, 45). Paralelamente, Avellaneda nos presenta a Carlota "que amó a Enrique, o mejor diremos, amó en Enrique el objeto ideal que le pintaba su imaginación" ( $a b, 152)$. Pero tanto la autora como su personaje "no dej[aron] de conocer harto pronto, que aquel[los] hombre[s] no era[n] grande[s] y amable[s] sino en [su] imaginación; que su talento era muy limitado, su sensibilidad muy común, sus virtudes muy problemáticas" (Autobiografia y cartas, 45-6).

Estas dos figuras femeninas son perfiladas como "alma[s] poética[s] [que] no amaría[n] largo tiempo a un hombre vulgar, pero se adivinaba también que tenía[n] tesoros en su imaginación bastantes a enriquecer a cualquier objeto a quien quisiera prodigarlos" (Sab, 152). La escritora expresa su escepticismo con respecto a la permanencia de los sentimientos humanos en su epistolario: "Yo comprendía, que el encanto que me inspirabas, ese perfume del amor, que se evapora como una esencia preciosa, debia forzosamente agotarse con el tiempo" (Autobiografia y cartas, 152-53). Como casi una transparencia, este mensaje se repite a través de la narradora en Sab, al referirse a las ilusiones destruidas de la mujer que, como Carlota, tiene el amor como única meta en la vida: " $i Y$ desgraciada de aquélla que es seducida por una engañosa semejanza!... Nada debe ser tan doloroso como ver destruido un error tan dulce, y por desgracia se destruye harto presto. Las ilusiones de un corazón ardiente son como las flores del estío: su perfume es más penetrante pero su existencia más pasajera" $(S a b, 152)$. Avellaneda considera tener una visión ingenua del amor: "Yo soy la criatura más fácil de engañar, o por 
lo menos de darse por engañada. Hago por creer todo aquello que me halaga, y no hay para mi estómago manjar indigesto con tal que me lo den con azúcar" (Autobiografia y cartas, 167). De modo similar, la descripción que la narradora hace de Carlota nos remite a esta actitud ingenua que se atribuye a sí misma: "Dotada de una imaginación fértil y activa, ignorante de la vida, en la edad en que la existencia no es más que sensaciones, se veía obligada a vivir de cálculo, de reflexión y de conveniencia" (Sab, 301-2).

De modo bastante inconsecuente, Avellaneda y Carlota se proyectan al mismo tiempo como dos mujeres caprichosas, incluso egoístas y arrastradas por sus desbordantes emociones. Por ello, en su constante y frustrada lucha por conquistar al difícil amante, Avellaneda declara: "No adivinarías tú con qué placer calmaría tus temores jurándote por mi amor [...] que nunca te dejaré, porque yo soy libre de fijarme en el país que me agrade, y madre, hermanos, patria, todo lo dejaría para habitar bajo el cielo que tú habitaras, si tú me dijeses que necesitabas mi presencia para ser feliz" (Autobiografia y cartas, 137). Casi de forma idéntica, Carlota manifiesta la efusión de sus sentimientos por Enrique Otway: "Mi padre, mi hermano, Teresa, Sab... ¿qué son todos al lado de tu amor? Yo no tengo ahora a nadie más que a ti... pero tú lo eres todo para el corazón de tu Carlota" (Sab, 297). La imagen que Avellaneda presenta de su amado en sus cartas, nos lleva a asumir que es una representación muy aproximada de Jorge Otway y su hijo Enrique. La escritora comenta, aludiendo a la actitud insensible y materialista de Cepeda: "El amor y la amistad, tal cual yo las considero, son otra cosa muy diferente de lo que ofrece el hombre material. ¿Eres tú capaz de comprender el sentimiento?... Lo creía ayer, y lo dudo ahora" (Autobiografia y cartas, 200). Asimismo, estos dos seres de ficción no expresan sus emociones abiertamente, no son nada idealistas y su principal meta es no arriesgar su estatus y asegurarse un porvenir de intereses económicos. En ambos casos, la escritora nos presenta su actitud excesiva y deplorable hacia las cosas, siempre "pegados a la tierra y alimentados de positivismo" (Sab, 304).

El personaje de Teresa, como Sab y Carlota, es otra posible variante del "yo" autobiográfico de Avellaneda. Representa la antítesis de Carlota. Durante los primeros capítulos de la novela se muestra como una figura enigmática, pasiva, casi muda, incapacitada para el amor, pero a medida que avanza la acción se transforma en un ser real, activo, con voz y con una gran capacidad de amar. La narradora la describe como "un alma altiva y fuerte 
[que] había dominado su destino y sus pasiones, y su elevado carácter, firme y decidido, le habla permitido alcanzar esta alta resignación que es tan difícil a las almas apasionadas como a los caracteres débiles" (Sab, 301). Avellaneda se describe a sí misma casi con las mismas palabras con que nos retrata a su personaje: "Tula tiene [...] un alma demasiado noble, demasiado altiva; tiene un corazón demasiado apasionado y lleno de delicadeza" (Autobiografia y cartas, 224). Teresa, como la escritora, no es correspondida por el hombre que ama, se siente aislada "sobre la tierra y necesit[a] igualmente compasión, amor y felicidad" (Sab, 258). La naturaleza del vínculo que Sab despierta en Teresa sirve como paralelismo al amor de la autora por Ignacio Cepeda: "Te juro que mortal ninguno ha tenido la influencia que tú sobre mi corazón. Tú eres mi amigo, mi hermano, mi confidente" (Autobiografla y cartas, 119). A pesar de la pasión que siente por Enrique Otway, Teresa, desenganiada de la sociedad en la que vive, descubre en Sab a un ser con cualidades nobles y admirables, sintiéndose vinculada hacia él. Teresa implora al mulato esclavo: "Déjame, pues, seguirte a remotos climas, al seno de los desiertos... jyo seré tu amiga, tu compañera, tu hermana!" (Sab, 258-59).

Los paralelismos entre la Autobiografia y cartas de Avellaneda y su novela $S a b$ se extienden más allá de los confines de la caracterización y pueden revelarse también en la semejanza de temas que preocuparon a la autora. Aunque, como ya hemos visto, el amor es el tema central, emergen otros enlazados con éste: opresión social, matrimonio y religión; temas de los que se desprende una notable preocupación por los problemas que afectan a la mujer. En Sab, la autora se identifica con el esclavo porque, como mujer, siente que pertenece "a aquella raza desventurada sin derechos de hombres" $(S a b, 137)$. Ella, que se siente limitada y frustrada en una sociedad que no reconoce la igualdad entre la mujer y el hombre, utiliza la metáfora del esclavo para enfrentarse a las leyes de la falocracia. Así emite una sonora protesta a través de su personaje: "Si el destino me hubiese abierto una senda cualquiera, me habría lanzado en [sic] ella... la tribuna o el campo de batalla, la pluma o la espada, la acción o el pensamiento... Todo me era igual: para todo hallaba en mí la actitud y la voluntad... jsólo me faltaba el poder!" (Sab, 312).

El sentimiento de alienación aflora en Sab como muestra del que Avellaneda admite experimentar en el seno de la sociedad: "Juzgada por la sociedad, que no me comprende, y cansada de un género de vida que acaso 
me ridiculiza; superior e inferior a mi sexo, me encuentro extranjera en el mundo y aislada en la naturaleza" (Autobiografia y cartas, 90). Este mensaje se hace resonancia en boca del mulato esclavo Sab al aludir a las injusticias ejercidas por la sociedad contra los de su raza: "Si al menos los hombres blancos, que desechan de sus sociedades al que nació teñida la tez de un color diferente, le dejasen tranquilo en sus bosques. [...] Esa es mi suerte. Superior a mi clase por mi naturaleza, inferior a las otras por mi destino, estoy solo en el mundo" ( $a b, 257-58$ ). Pero cuando Sab ataca a la sociedad, no lo hace por su condición de esclavo, sino por la frustración que siente ante la imposibilidad de conseguir el amor de Carlota. Sobre esa superioridad que siente la creadora y su personaje, comenta Carmen Bravo-Villasante: "El hombre superior parece aniquilado por su gran pasión, en pugna con una sociedad inferior, que no comparte las pasiones ni las comprende, y que trata de anular a los apasionados" (Bravo-Villasante, 20). El mulato esclavo, como Avellaneda, actúa motivado por sus sentimientos y emociones, asomándose como un ser feminizado, ya que "enamorarse, naturalmente, implic[a] un riesgo de flaqueza." $12 \mathrm{La}$ autora se declara en su epistolario y autobiografía hostigada por unos cánones sociales que la oprimen. Por ello, en una de sus cartas propone a Cepeda escapar de esas imposiciones sociales que les niegan la felicidad: "Cepeda, dejemos esta horrible vida, este mundo en el cual ya estaríamos separados por una barrera insuperable" (Autobiografia y cartas, 138). Simultáneamente, Sab desea huir de esos impedimentos sociales que hacen de él una víctima por el color de su piel y desprecian sus sentimientos de hombre. Sab confiesa a Teresa: "SI, vos no sabéis qué [...] sueños de cruel felicidad han salido de mi cabeza abrasada... [...] arrancar [a Carlota] de esa sociedad que se interpone entre los dos, huir a los desiertos llevando en mis brazos a ese ángel de inocencia y de amor..." (Sab, 246).

En su novela $S a b$, Avellaneda no sólamente se opone a esa sociedad opresora, sino que propone una nueva sociedad moderna que gobierne con justicia y equidad para todos, exigiendo el derrumbamiento de esos cánones sociales que, según su actitud inconformista, han demostrado ser una trampa institucionalizada. El esclavo Sab exclama: "No siempre reinareis en el mundo, error, ignorancia y absurdas preocupaciones: vuestra decrepitud anuncia vuestra ruina. [...] Los viejos idolos caerán de sus inmundos altares y el trono de la justicia se alzará brillante, sobre las ruinas de las viejas sociedades"(Sab, 317). En sus cartas, la autora expresa igualmente el rechazo de una sociedad 
patriarcal a través de una visión negativa de los hombres: "Si yo desdeño la opinión del vulgo, es porque conozco a los hombres: conociéndolos no es posible ni temerlos ni respetarlos" (Autobiografia y cartas, 197-98). Casi de forma análoga, su personaje Teresa, intentando abrir los ojos de la inocente Carlota al mundo, le aconseja: "Los hombres son malos, Carlota, pero no debes aborrecerlos ni desalentarte en tu camino. Es útil conocerlos y no pedirles más que aquello que pueden dar" (Sab, 306). Este consejo resalta la actitud romántica de Teresa para la que "el mundo tiene estructura típicamente maniquea, se compone de malos, los hombres, y de buenos, las mujeres. [...] Y, siendo éste el estado natural de las cosas, a la mujer no le queda sino resignarse. La propuesta de Teresa es la de una vida interior plena, que ignore el mundo exterior negativo" (Torres-Pou, 59). Esta visión de los hombres de Teresa coincide con la voz de la narradora, descubriéndose una identificación de Teresa con la voz autorial.

La figura de Avellaneda, como Carlota, es revelada como un ejemplo representativo de la situación de la mujer burguesa en una sociedad que le asigna un papel meramente decorativo y que halaga su pasividad. Sin embargo, y a pesar de todos los lujos y comodidades entre los que vive, se siente "abrumada con el peso de una vida tan llena de todo, excepto de felicidad; resistiendo con trabajo a la necesidad de dejarla; buscando lo que despreci[a], sin esperanzas de hallar lo que ansí[a]; adulada por un lado, destrozad[a] por otro; [...] cansada, aburrida, incensada y mordida sin cesar..." (Autobiografia y cartas, 171). Carlota también se siente alejada de una sociedad que la oprime y a la vez le exige resignación: "Carlota [no] debía quejarse de su suerte, pero a pesar suyo se sentía oprimida por todo lo que tenía de serio y material aquella vida del comercio" ( $S a b, 302)$. De modo semejante al de su personaje, la autora se define desgraciada y abrumada por la presión de la sociedad. En una de sus cartas, exclama: "Envejecida a los 30 años, siento que me cabrá la suerte de sobrevivirme a mi propia, si en un momento de absoluto fastidio no salgo de súbito de este mundo tan pequeño, tan insuficiente para dar felicidad, y tan grande y tan fecundo para llenarse y verter amarguras" (Autobiografia y cartas, 171). Asimismo, Teresa, antes de morir, reflexiona: "Nada poseo, nada puedo legar a la compañera de mi juventud. Pero acaso pueda dejarle un extraño consuelo, un triste pero poderoso auxilio contra el mal que marchita sus años más hermosos. Carlota, tú estás cansada de la vida, y detestas al mundo y a los hombres..." (Sab, 305). Avellaneda y su per- 
sonaje parecen encontrar paz y tranquilidad escapándose a la naturaleza, a ese ámbito libre de la opresión y relegación social. Avellaneda dice en otra de sus cartas: "Tampoco me sería ingrato irme a una pobre aldea a criar pichones y a cultivar flores" (Autobiografia y cartas, 175-76). Pensando en Carlota la narradora comenta: "En Bellavista respiraba más libremente; sentía su pobre corazón necesidad de entregarse, y ella le abría al cielo, al aire libre del campo, a los árboles y a las flores" (Sab, 304).

Paradojicamente, Avellaneda, como Carlota, "hastiada del mundo; despreciando todos sus oropeles; necesitada de reposo y paz; anhelante de grandes objetos," no se decide a romper en definitiva con esos códigos sociales que la relega a un segundo plano y "sig[ue] [allí] en medio de las pequeñeces tumultuosas de la vida social, que [le] pesa, que [le] fastidia" (Autobiografia y cartas, 237). A pesar de que Carlota "tocó toda la desnudez, toda la pequeñez de las realidades, comprendió lo erróneo de todos los entusiasmos," se resigna a su estado de subordinación e infelicidad (Sab, 304). Además, la sociedad le impone como norma "callar delante de los hombres," siendo su único consuelo "llorar libremente dentro de los muros del convento de las Ursulinas" ( $\mathrm{Sab}, 301)$. Igualmente, Avellaneda busca en la vida retirada su insatisfacción por la sociedad. En una de sus cartas así lo expresa: "El cansancio del mundo, el hastío de la realidad de esta pícara existencia y el vacío profundo de mi pobre corazón, que tanto ha amado y tan mal ha sido comprendido, todo se reúne para inspirarme lejanía de la sociedad y afecto al retiro" (Autobiografia y cartas, 240).

Otra constante en su Autobiografia y cartas y en su novela $S a b$ es el tema del matrimonio. La autora parece rebelarse desde muy temprana edad contra los convencionalismos sociales que permititían que los padres forzaran a los hijos a casarse por intereses económicos. A través de Jorge Otway, padre de Enrique, la escritora censura los matrimonios por conveniencia. Así ordena el padre a su hijo, refiriéndose a su boda concertada con Carlota: "No te casarás con Carlota de B... mientras haya otras varias en que escoger, tan buenas y más ricas que ella" ( $a b, 182)$. Alusiones similares asoman en su autobiografía, cuando la escritora menciona el "proyecto de [su] tío Felipe de casar[la] en Constantina con un mayorazgo del país, y de cómo [su] hermano, que tan opuesto era a que [ella] [se] casase, tomó un empeño entonces a favor de [su] novio" (Autobiografia y cartas, 75). Pero ésta no fue la única vez en que Avellaneda se declara víctima de un matrimonio forzado. Cuando 
apenas tenía 14 años, su familia decidió su porvenir "[tratándola] casamiento con un pariente lejano [...] [reputado] el mejor partido del país" (Autobiografia y cartas, 44-5). La autora se opuso a tal compromiso y como consecuencia su abuelo la desheredó: "Todo el mundo decía, que mi locura en romper el matrimonio había privado a mamá del tercio de mi abuelo y a mí misma de su quinto" (Autobiografia y cartas, 60). Por otra parte, la familia de Carlota se opone a su matrimonio con Enrique Otway por el hecho de que éste no perteneza a la misma clase que ella, pero "todos los esfuerzos empleados por [su] familia para apartarla de Enrique fueron inútiles" (Sab, 153). Por consiguiente, el tío de Carlota "hizo un testamento a favor de los hijos de otro hermano para quitar a Carlota toda esperanza de su sucesión" $(S a b, 154)$.

Pero Avellaneda no sólo parece rechazar el matrimonio basado en intereses económicos, sino como institución social que esclaviza a la mujer. Por esta razón, la autora hace que Sab exprese esta visión del matrimonio, estableciendo un claro paralelismo entre la esclavitud del negro y la subyugación social de la mujer blanca: “ $\mathrm{OOh}$, las mujeres! ${ }_{\mathrm{i}}$ obres y ciegas víctimas! Como los esclavos, ellas arrastran pacientemente su cadena y bajan la cabeza bajo el yugo de las leyes humanas" (Sab, 316). La escritora se opone a esa actitud de servidumbre que el matrimonio impone a la mujer. En su epistolario íntimo admite: "Soy libre, y lo eres tú; libres debemos ser ambos siempre; y el hombre que adquiere un derecho para humillar a una mujer, el hombre que abusa de su poder, arranca a la mujer esa preciosa libertad; porque no es ya libre quien reconoce un dueño" (Autobiografla y cartas, 130). A la mujer de la época se la educaba para que sólo ambicionara el amor y el matrimonio como único objetivo de su vida. Curiosamente, la propia autora se nos insinúa con grandes deseos de conseguir el amor de su amado, sientiéndose frustrada y decepcionada al no ser correspondida: "Te amé y me creí feliz, y creía que tenía el poder de darte lo que de ti recibía: alegría, esperanza, ilusiones, felicidad... ¡Oh, qué crueldad es la tuya en arrancarme de este dulce error y en arrojar sobre mi naciente ventura el velo negro y fúnebre de la desconfianza y la desilusión" (Autobiografia y cartas, 135). Casi estas mismas palabras brotan en Teresa, quien conociendo las ilusiones de Carlota, se opone a la intención de Sab de revelarle el engaño de su relación con Enrique: “QQuién te da el derecho de arrancarla [sic] sus ilusiones, de privarla de los momentos de felicidad que ellas pueden proporcionarla [sic]? ¿qué habrás logrado cuando 
la despiertes de ese sueño de amor, que es su única existencia? ¿qué le darás a cambio de las esperanzas que le robes? ¡Oh, desgraciado el hombre que anticipa a otro el terrible día del desengaño!" (Sab, 256).

Carlota representa la triste realidad de esas mujeres que, volcándose plenamente hacia el amor, descubren la enormidad de su engaño, y a las que no les queda otra opción que la de la resignación. Se siente emocionalmente frustrada en su matrimonio al "[descubrir] a su esposo más ocupado de su fortuna que de su amor" (Sab, 302). Además es desgraciada al "[ver] a su marido tal como [es]. [Comienza] a comprender la vida. Sus sueńos se $\operatorname{disip}[\mathrm{an}]$, su amor huy[e] con su felicidad" (Sab, 304). Y aunque no se atreve a "quejarse de su suerte, [...] se [siente] oprimida por todo lo que [tiene] de serio y material aquella vida del comercio," no quedándole otro consuelo que "llorar en el seno de su amiga sus ilusiones perdidas" ( $S a b, 302)$. La misma Avellaneda se habla encontrado en una situación similar cuando se convence de que sus sentimientos nunca podrán ser correspondidos: "He visto huir de tu corazón el amor, y, si he llorado, no he osado al menos quejarme. [...] Siento yo misma entibiarse mi corazón progresivamente con la frialdad del tuyo, y preveo la destrucción de mis últimas ilusiones; pero me resigno" (Autobiografia y cartas, 154).

Avellaneda se muestra insatisfecha en una sociedad, cuyas leyes, injustas y opresivas, discriminan a determinados seres humanos. Así lo expone a través de las palabras del esclavo Sab, quien utiliza la religión para defender la igualdad entre todos los hombres, sea cual sea su color y sexo: "Dios, cuya mano suprema ha repartido sus beneficios con equidad sobre todos los países del globo, que hace salir al sol para toda su gran familia dispersa sobre la tierra, [...] Dios, ¿podrá sancionar los códigos inicuos en los que el hombre funda sus derechos para comprar y vender al hombre? [...] No he podido encontrar entre los hombres la gran armonía que Dios ha establecido en la naturaleza" (Sab, 309-10). Esta visión deteriorada de la sociedad se aprecia asimismo en su epistolario íntimo, cuando arguye: "Si el mundo fuese más puro, más santo; si volviésemos a la edad de inocencia en que este mundo viejo y corrompido era aún joven y puro, entonces yo no sé cuáles serían mis opiniones; pero hoy día sé que el hombre [...] puede hacerse culpable de egoísmo y crueldad cuando se reviste con el derecho de superioridad" (Autobiografia y cartas, 130). Este mismo contraste entre la visión positiva de la religión y la imagen perversa de la sociedad es expresado por el esclavo Sab: 
"Pero si no es Dios, [...] si son los hombres los que me han formado este destino, si ellos han cortado las alas que Dios concedió a mi alma, si ellos han levantado un muro de errores y preocupaciones entre mí y el destino que la providencia me había señalado, si ellos han hecho inútiles los dones de Dios [...]. Si son los hombres los que me han impuesto este terrible destino, ellos son los que deben temer al presentarse delante de Dios" (Sab, 315). En otra de las cartas de la escritora aparece un sentimiento similar: "La sociedad me hastía; por un sentimiento de religión lucho contra el desprecio que me inspiran los hombres, pero no puedo estimarlos. ¡He visto en ellos tanta pequenez! ¡He sido víctima de tan mezquinas y ruines pasiones!... (Autobiografia y cartas, 218).

En conclusión, y a la vista de todo lo expuesto, es evidente que la novela Sab de Gertrudis Gómez de Avellaneda, considerada, sin duda alguna, una obra de pura ficción, ofrece un fiel paralelismo con su Autobiografia y cartas, tanto desde el punto de vista de la caracterización de sus personajes como de la temática de carácter social que preocupó a la autora en su momento. Al haberse considerado que $S a b$ pertenece al género novelístico más que al autobiográfico, y tras haberse demostrado que constituye un reflejo de la Autobiografia y cartas de la escritora, todo parece indicar que éstas también podrían considerarse una obra de ficción, tal y como lo confirma Emil Volek: "Las estrategias literarias, las máscaras románticas y los múltiples valores discursivos y estéticos creados por el azar histórico, han ficcionalizado estas cartas." ${ }^{13}$ Sin embargo, en nuestro análisis final, y ante la imposibilidad de cuestionar la teoría de Frye por la escasez de datos biográficos verificables, es igualmente imposible dar por cierta su teoría de que "la mayor parte de las autobiografias se inspiran en un impulso [...] novelístico," al haber conseguido sólo establecer ciertas similitudes entre la reconocida obra de ficción Sab y la Autobiografia y cartas de la autora, ya que, por la misma razón, se podría llegar a demostrar que la novela es plenamente autobiográfica. 


\section{NOTAS}

1 "La mayor parte de las autobiografias se inspiran en un impulso creativo, y por lo tanto novelistico, que tiende a seleccionar sólo aquellos acontecimientos y experiencias de la vida del escritor que constituyan una estructura integrada; estructura que puede, por un lado, superar la imagen con la que el escritor se identifica a sí mismo o, por orro, reflejar simplemente la coherencia de su personalidad y sus actitudes." La traducción es mía. Northrop Frye, "Specific Continuous Forms" in Arnold Kettle (ed.), The Nineteenth-Century Novel (London: The Open University Press, 1972), 28.

2 Véase Mary S. Vázquez, "Epistolaridad, marginación y deseo en un cuento de Carmen Riera", Cuadernos de ALDEU, X (1994): 215.

3 Lucía Guerra, "Estrategias femeninas en la elaboración del sujeto romántico en la obra de Gertrudis Gómez de Avellaneda", Revista Iberoamericana, 132-133 (1985): 722. El Censor Regio de Imprenta, Licenciado Hilario de Cisneros Saco, decreta en septiembre de 1844 la prohibición de Saby Dos mujeres en Cuba "por contener la primera doctrinas subversivas del sistema de esclavitud de esta Isla y contrarias a la moral y buenas costumbres, y la segunda por estar plagada de doctrinas inmorales." (Mary Cruz, prólogo y notas a Sab (La Habana: Instituto Cubano del Libro, 1973), 49-50.

4 Gertrudis Gómez de Avellaneda, Autobiografia y cartas, con un prólogo y una necrología de Lorenzo Cruz de Fuentes, $2^{\mathrm{a}}$ ed. (Madrid: Imprenta Helénica, 1914), 242.

5 Mencionado por Carmen Bravo-Villasante en su prólogo y notas a Sab (Salamanca: Anaya, 1970), 31.

6 Gómez de Avellaneda, Sab (La Habana: Instituto Cubano del Libro, 1973), 139.

7 Doris Sommer, "Sab c'est moi", Hispamerica 16 (1987): 28.

8 Joan Torres-Pou, "La ambigüedad del mensaje feminista de Sab de Gertrudis Gómez de Avellaneda", Letras Femeninas, 19 (1993): 58.

9 Carmelo Virgillo, "El amor en la estética de la Avellaneda", Cuadernos Americanos, 219 (1978): 252.

10 Carmen Bravo-Villasante, prólogo y notas a Sab (Salamanca: Anaya, 1970), 19.

11 Citado por José Antonio Portuondo, "El negro, héroe, bufón y persona en la literatura cubana colonial", Union, 4 (1968): 3.

12 Julio Mafud, "El machismo argentino", Mundo Nuevo, 16 (1967): 77.

13 Emil Volek, "Cartas de amor de la Avellaneda", Cuadernos Hispanoamericanos, 511-16 (1993): 112-13. 